\title{
Technology Enhanced Classroom for Low-Income Children's Mathematical Content Learning: A Case Study
}

\author{
Sam Clark and Lena Lee
}

\begin{abstract}
This paper is about teaching third-grade Common Core mathematical content as the learning goal of mathematics (NCTM, 2014) by using digital media - namely, tablets-in a low-income urban school classroom. The Substitution, Augmentation, Modification, and Redefinition (SAMR) model was used for the technology aspect of this paper, which presents how these instructional methods were adapted to the teacher's modeling and encouragement of the children's authorship in learning mathematics.
\end{abstract}

Index Terms-Mathematical learning, low-income children, digital media.

\section{INTRODUCTION}

Many ongoing discussions have been about implementing new technology in the classroom to enhance students' learning [1]-[5]. In particular, children born in the modern technology era have had more exposure to, and use of, digital media than any previous generation. It is therefore critical for us, the teachers, to ponder questions that consider how differently young children play, learn, and communicate and what helps them learn best with newest technological tools [6].

This exposure of these children to technology is more critical in classrooms of children from low-income families, considering the significant discrepancies to date in their socioeconomic status (SES) and limited experience in using technology and digital media for learning [7], [8].

The majority of the children in this project had a lower SES and most of them had more disadvantages due to this status and difficult circumstances [9]. These factors most likely caused their parents to participate less in, or engage less with, their schooling and other educational activities because of their work schedules, limited financial resources, unfamiliarity with the education system, different languages, and different cultural values and expectations [10]. In considering how to deal with this situation, we believe that using an effective, SAMR technology-enhanced curriculum will foster low-income children's interest in learning.

To create this new curriculum, the children must learn how to use technology appropriately within the teachers' pedagogical modeling and instructional scaffolding. As preparation, teachers at schools with many low-income families, or in urban communities, need to create a learning

Manuscript received May 11, 2018; revised August 1, 2018. This work was supported in part by the PNC Foundation.

Sam Clark is with Greensview Elementary School, Upper Arlington, $\mathrm{OH}$ USA (e-mail: sclark@uaschools.org).

Lena Lee is with Department of Teacher Education, at Miami University, OH USA (e-mail: leel@miamioh.edu). environment that provides a way for their students to build self-confidence and self-regulation, as both attributes are crucial for learning mathematics. Without fundamental skills, these children cannot learn well or accomplish what is expected of them at school. A solid self-awareness lets children share knowledge with their peers and teachers in a technologically enhanced classroom.

To prove our main point, we tell the story of teaching third-grade Common Core mathematical content using digital media through the SAMR Model as the focus of learning goals for mathematics [11]. It is important to note that this paper aims not to report any quantitative data analysis but to provide a practical idea to implement in a classroom whose students are from diverse backgrounds including those of SES and ethnicity/race. This story is about 25 students and one teacher at a school in a Midwestern area where all students in this project receive free breakfast and lunch, a signifier of low SES. The students present in this project were in one of two, 25 student classes; with nearly $70 \%$ of students being Black, $20 \%$ White, and $15 \%$ Hispanic.

In looking at this story, we adopted the SAMR Model [12] as our framework to develop and implement our project. The SAMR Model includes the use of technology as an effective teaching and learning tool. As part of adopting the SAMR Model for the classroom instructions discussed in this paper, we attempted to demonstrate the impact of using digital media applications on the students' ability to learning mathematical concepts and foster a deeper understanding of these concepts.

From among the various types of digital media tools, the Amazon Fire Tablet was chosen, due to its reasonable cost and good functional qualities that support young children's learning and handling of this device. The teacher acquired 25 tablets through a funding project that was initiated to ensure a one-to-one technology to student ratio in the classroom.

\section{INSTRUCTIONAL PROCESS USING THE SAMR MODEL}

Our goal in using digital media into the classroom was to increase students' engagement while working independently to achieve meaningful and responsible mathematical learning. In the following sections, we discuss our plan and how we exposed the children to the tablets in purposeful instructional ways with the SAMR Model. Although the four stages of the SAMR Model are progressive, we understand that they can be either emergent or entangling or both, depending on each classroom's circumstances, teaching goals, and students' needs. The process we discuss below can be of significant help to students who started using a tablet for learning math for the first time.

Of note, even though a teacher's modeling should be 
ongoing, the plan we share herein lasted only four days because its emphasis was on how to get children to increase their self-regulation and responsibility while learning to use digital media effectively. Each day, the plan was not a day-long matter as the teachers could modify the plan depending on their class schedules, the students' needs, and the teaching objectives.

\section{A. Day 1: Substitution}

For the first stage of SAMR (substitution), the teacher replaced traditional flash cards with Amazon Fire Tablets full of applications and games to enhance fact fluency. To make this work efficiently, the teacher designed an instructional time to create and convey clear expectations before the students received their tablets. During this time, the teacher discussed why the class needed rules and expectations for using the tablets and modeled how to use the tablets in class.

For instance, the class had three specific and ongoing rules for using the tablets: 1) the tablets should always remain on a group table, 2) they should only be used for whatever the teacher assigned, and 3) there would be one tablet per student. These rules allowed the students to prepare mentally for learning by using the digital media [12]. In addition, they learned the techniques and functionalities for the effective use of a tablet. At the outset, the teacher spent 10 to 15 minutes explaining the main features of using the tablets and answered the students' questions.

Following this informational activity, each student received a tablet to begin exploring as part of the total class. Using a classroom computer and projector, the teacher guided the students through each step of using the tablet starting with the basics to make sure that everyone could understand what was expected. This first step included how to turn on the tablets and open apps for more complex features, and how each new feature worked on the tablet (see Fig. 1 for the student working on the tablet).

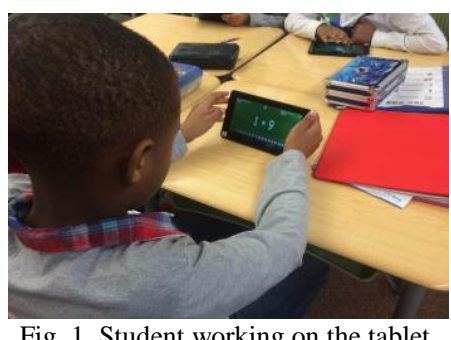

After this introductory process, all students played with their tablets for 25 minutes to explore it while the teacher helped to troubleshoot any issues and answer any questions.

\section{B. Day 2: Augmentation and Modification}

After the Day 1 instructions, Day 2 was spent introducing and using each tablet application so that students could implement the instructions and build on what they had learned. The instructions on Day 2 let them go beyond their new awareness of using this new digital media tool. The students were encouraged to learn a new work habit that could transform their learning: augmentation.

First, the class looked at apps and learned the targets one by one-in this case, increasing factual mathematical fluency with multiplication, division, addition, and subtraction (see
Fig. 2 below for tablet app content examples). Similar to Day 1 , the teacher spent time showing the students exactly how to use the apps effectively. Second, each student had a tablet and went through each step of using the app as the teacher demonstrated. Third, the students were given a specific mathematical operation based on their ability and performance, and then they began using the apps.

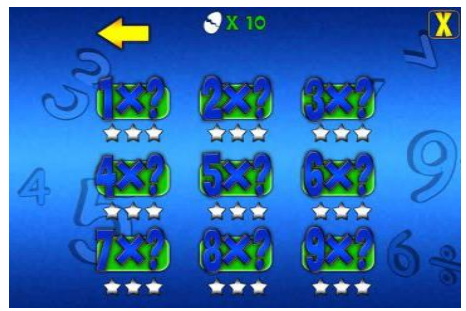

Fig. 2. Problem example of factual mathematical fluency.

As part of modification, students who needed extra practice with their addition and subtraction before moving on to multiplication or division spent their time completing these tasks. Those who had grade-level performance focused on practicing multiplication and division. This step was very crucial in clarifying problems or struggles in learning [11] because, after this process, students were continued to use the tablet's apps effectively. These tablets allowed students to improve their mathematical fact instruction due to the speed of problems and the instant feedback given via the Apps. Students having improved practice and receiving instant feedback is an important aspect of the Augmentation and Modification stages of the SAMR model.

\section{Day 3 and 4: Redefinition}

On Day 3, the class used an app with a learning target of identifying fractions or shapes and the identification of such shapes (see Fig. 3 for the tablet app's content example). The teacher modeled on each step of this application. Then the students were encouraged to remember the expectations of self-regulated and self-directed learning when using a tablet They spent time on working individually with the app. The teacher was always available to answer any questions. For their part, the students soon started to "redefine" their way of learning by means of this continual instructional process.

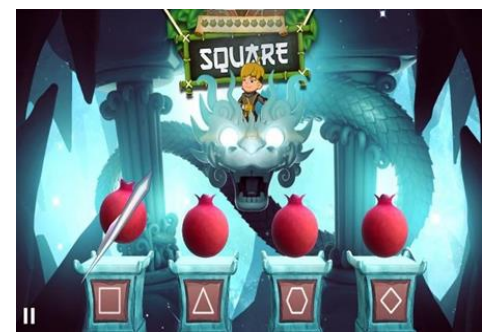

Fig. 3. Tablet app's content example.

Day 4 offered an online curriculum program provided and supported by the school district as supplemental learning materials to see if students could accomplish their tasks by solving problems from different sources and other types of materials than the tablets' apps [11]. Like the apps the class used, this new online program also gave immediate feedback to students and their teacher. In addition, the format was similar to the mathematical questions on the state achievement test the students had to take at the end of the year. 
As a result, they had the opportunity to apply the knowledge that they gained from the tablets' apps to practice within different settings, different from the traditional paper and pencil assessments.

The teacher used both assessments of the program and the tablet apps to understand the standards the students were meeting and the areas in which they were struggling. This evaluation data was also used effectively by the teacher to provide direct, meaningful math instruction for individuals and small groups. After Day 4, the teacher used this new way of instruction throughout the academic year.

\section{Student LEARNING PROCESS WITH SELF-REGULATION AND RESPONSIBILITY}

Following several days of modeling and scaffolding, the tablets were put into the everyday classroom routine during math learning center time. These tablets became a station for the math learning centers where each student could rotate through and become more skillful in using the learning center [11]. On any day, six to eight students would be working independently on their tablets (see Fig. 4 for the students working independently).

Each day, the tablet center had a mathematical learning target that the students were expected to master. For instance, one student learning target consisted of "I will increase my fact (insert operation) fluency by completing fast math on the tablet," or "I will be able to identify fractions by correctly identifying parts of a shaded whole," or "I will read and answer practice questions using the online program."

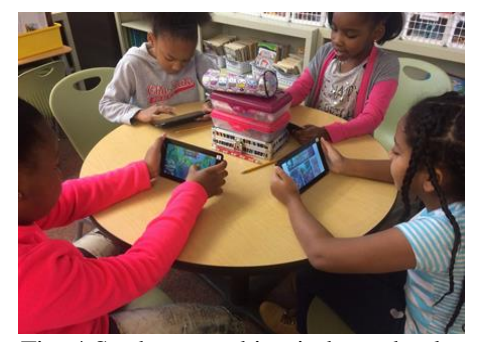

Fig. 4 Students working independently.

When assigned to the tablet center, students understood that they would be responsible for their learning target. They independently logged into the tablets and began working on the correct application without any guidance from the teacher; they acquired these skills from the class time purposely designed for introducing the tablets before implementation. All the apps were used with children's self-monitoring and correction. When a student wanted to have more support to solve a problem after their first attempts with the apps' directions, they could work with their peers and the teacher to resolve their struggles by focusing more on the particular parts of independent work.

The tablets were also used in the classroom as an extension tool when students would finish other traditional work tasks, such as worksheets, workbook assignments, or math games. Whenever they needed to complete other tasks, they were more than eager to go and use them. Students located the learning target for the day and began working on the tablet just as if they were at the tablet center. Because each student was assigned to a specific tablet, the teacher could efficiently track their completion and assess their results appropriately on each application, saving the students and teacher time and organization. The data gathered from the district-wide online curriculum was also used to monitor the progress of students' growth throughout the school year.

After this differentiated instruction was provided by the teacher, the students were more aware of what they did and did not know and why. This self-awareness of learning led them to have a better understanding of and accountability for solving a problem. In this way, they could effectively and strategically approach which applications and content they needed to focus on for improvement during independent tablet time.

The tablet center also offered extra motivation for students to concentrate on tasks throughout mathematical content learning because of their excitement and engagement with the tablets, which they loved to use. They often did not view it as tedious learning. Instead, they viewed it as play [13]. The SAMR model and tablet use was more helpful, particularly for the low-achieving students who often failed in such traditional instructional tasks as worksheets and paper-and-pencil tests. They intended to work with the tablet app tasks they knew they would eventually succeed with by themselves.

Students often asked "Are we using the tablets today?" and "Can we get on the tablets instead of having recess today?" or "When can I start my multiplication facts on the tablet today?" Many students often discussed their progress on the variety of applications with their peers, showing a sense of pride and accomplishment of their work and supporting each other. "I mastered all of my nine facts today and unlocked two new levels" was the dialogue that was often heard in the classroom, hallway, cafeteria, and even playground.

\section{CONCLUSION}

By having nearly a semester of instruction with the use of tablets as a part of the everyday classroom, we certainly recognized effective and successful mathematical improvements. The students' active participation with the instructions, high level of independence and ownership on learning in class were clearly evidenced. By years end, over $80 \%$ of students were fluent in the multiplication facts 1-10 with accuracy of $85 \%$ or higher.

Furthermore, another assessment result--that of the state achievement tests at the end of the school year-also showed the students' improvement. These students scored an average of three points higher than classroom students who were instructed with traditional instruction on their math Measure of Annual Progress (MAP) assessment. These scores were the equivalent of $1 / 4$ of a year's growth in math, in comparison to those students who did not use tablets during instruction. Moreover, on the same MAP assessments, $68 \%$ of students who used the tablets successfully showed one year's growth in third grade math content curriculum in comparison to only $55 \%$ of students who did not use the tablets. These are fascinating results in particular for these students in a low-income urban school. With the implementation of technology in this classroom through the SAMR model, the 
students' more active engagement in and responsibility for math learning, in turn, resulted in overall math achievement improvement foremost students.

We initiated this instructional approach from our beliefs and intentions to use technology to enhance the learning of children who are from low-income families or schools. In spite of its short time of instruction and small student number, this study allowed us to see a possibility to adopt novel instructional technology successfully with the teacher's purposeful modeling and scaffolding. Their sound self-awareness and accountability for their mathematical learning also encouraged these students to obtain constructive and cooperative learning in their technologically-enhanced classrooms.

\section{REFERENCES}

[1] R. Berson and M. J. Berson, High-Tech Tots: Childhood in a Digital World, Charlotte, NC: Information Age Publishing, 2010.

[2] C. Donohue, Technology and Digital Media in the Early Years: Tools for Teaching and Learning, New York, NY: Routledge, 2015.

[3] P. Lisenbee, "Whiteboards and websites: Digital tools for the early childhood curriculum," Young Children, vol. 64, no. 5. pp. 92-95, 2009.

[4] National Association of the Education for Young Children. (2012). Technology and interactive media as tools in early childhood programs serving children from birth through age 8. [Online]. Available: http://www.naeyc.org/files/naeyc/PS_technology_WEB.pdf

[5] Rideout, A. Lauricella, and E. Wartella, "Children, media, and race: Media use among White, Black, Hispanic, and Asian American children," presented at Lambert Family Communication Conference on Children, Media and Race, Washington D.C., 2011.

[6] L. Lee, "Young children, play, and technology: Meaningful ways of using technology and digital media," Play from Birth to Twelve: Contexts, Perspectives, and Meanings, New York, NY: Routledge, 2015, pp. 217-224.

[7] U.S. Department of Commerce, Falling through the Net: Toward Digital Inclusion, Washington, DC: U.S., GPO, 2000.

[8] J. Rideout and E. Hamel, "The media family: Electronic media in the lives of infants, toddlers, preschoolers and their parents," Menlo Park, CA: Kaiser Family Foundation, 2006.

[9] C. M. McWanyneand and Melzi,G, "Validation of a culture-contextualized measure of family engagement in the early learning of low-income Latino children," Journal of Family Psychology, vol. 28, no. 2, pp. 260-266, 2014.

[10] L. Lee, "Technology and hands-on curriculum approaches for teaching young latino preschool children," International Handbook of Learning with Technology in Early Childhood Theory and Method., New York: Routledge, in press.

[11] National Council of Teachers of Mathematics. (2014). Principles to actions. [Online]. Available: https://www.nctm.org/uploadedFiles/Standards_and_Positions/PtAEx ecutiveSummary.pdf

[12] R. Puentedura. (2014). Learning, technology, and the SAMR model: Goals, processes, and practice. [Online]. Available: https://www.hippasus,com/rrpweblog/archives/2014/06/29/LearningT echnologySAMRModel.pdf

[13] L. Lee, "It is a learning Journey for all": A lesson from American elementary teachers who used a classroom Wiki," Journal of Interactive Online Learning, vol. 11, no. 3, 2012.

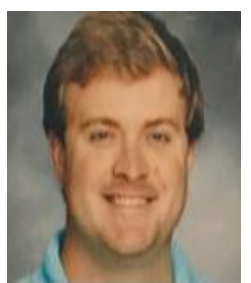

Sam Clark is a 5th grade teacher in Columbus, Ohio. He has spent the previous four school years teaching 3rd, 4th, and 5th grades respectfully at Whitehall City Schools. Prior to working at Whitehall City Schools Sam attended Miami University in Oxford, Ohio, where he received his Bachelors of Science in Early Childhood Education. Sam continued his education at Walsh University in Canton, Ohio to receive his 4th and 5th grade Generalist Endorsement.

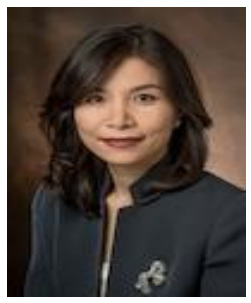

Lena Lee is a professor of early childhood education at Miami University of Ohio, USA. She earned the doctorate of early childhood education in Indiana University, Bloomington, USA, and the D.E.A of Comparative Women's Studies at Paris VIII University, France. Her foci of research, teaching, and professional service are on education and lives of young children who are socially and culturally marginalized in various global contexts. She has been working on the extremal grant project, LIPE [Low-Income Preschool Enhancement] funded by the PNC Bank Foundation since 2014 to support young low-income preschoolers who are from diverse backgrounds in Ohio. She was the first awardee of Emerging Scholar Award of American Educational Research Association (AERA), Critical Perspective of Early Childhood Education SIG. She has been elected as the Region 5 (Illinois, Indiana, Michigan, Minnesota, Ohio, \& Wisconsin) Representative at the National Association for Early Childhood Teacher Educators (NAECTE) and as the Vice present of The Korean-American Early Childhood Education Researchers Association (KECERA). She also serves as co-representative of the Region 2 (Illinois, Indiana, Michigan, Ohio, \& Wisconsin) at OMEP-USA (Organisation Mondial Pour L'Education Prescolaire) World Assembly and International Conference and a Co-International Representative of USA at Digitalising Early Childhood International Conference. Her works have been published in well-known journals such as Multicultural Education, Journal of Interactive Online Learning, Journal of Early Childhood Research, and Early Childhood Education Journal. 